\title{
Note from the Editor: Lasswell Prize announcement for volume $46(2013)$
}

The Harold D. Lasswell Prize is awarded to the best article in each volume of Policy Sciences that contributes most to the theory and practice of the policy sciences, as determined by a vote of the journal's international editorial board. A monetary award of $\$ 500$ is provided by the journal's publisher, Springer, to the awardee. It gives me great pleasure to announce that the winners of the 28th annual prize are Reinhard Steurer for his article, "Disentangling governance: a synoptic view of regulation by government, business and civil society" Issue 1 and Miriam Fischlein and Timothy M. Smith for their article, "Revisiting renewable portfolio standard effectiveness: policy design and outcome specification matter" in Issue 3. The Prize is named in honor of Harold D. Lasswell (1902-1978), a founder of this journal and noted contributor to the policy sciences. The authors of the two articles will split the $\$ 500$ prize. 